\title{
A COMPARATIVE STUDY OF AUTOMATION STRATEGIES AT VOLKSWAGEN IN GERMANY AND SOUTH AFRICA
}

\author{
O. Wessel ${ }^{1}$ and I. Gorlach \\ School of Engineering \\ Nelson Mandela Metropolitan University, South Africa \\ igor.gorlach@nmmu.ac.za
}

\begin{abstract}
The final car assembly lines at Volkswagen's production sites in Germany and South Africa are analysed to determine the best automation level based on cost, productivity, quality, and flexibility for a plant location. The methodology used is proposed by the Fraunhofer Institute. The final assembly processes are analysed and classified according to the automation level. The operations are evaluated at every level of automation based on information from existing factories. If the best levels of automation for all the parameters correspond, the optimal level of automation for a plant is reached. Otherwise, improvements and/or additional considerations are required to optimise the automation level. The result of the analysis indicates that the highest automation level is not necessarily the best in terms of cost and quality, and some de-automation is required. The analysis also shows that a low automation level can result in poor product quality and low productivity. The best automation strategy should be based on the analysis of all the aspects of the process in the local context.
\end{abstract}

\section{OPSOMMING}

Die finale monteerlyne by Volkswagen se aanlegte in Duitsland en Suid-Afrika is ontleed om die beste outomatisasievlak te bepaal gebaseer op koste, produktiwiteit, gehalte en aanpasbaarheid gegee die ligging. Die metodologie wat gevolg is, word voorgestel deur die Fraunhofer Instituut. Die finale monteerprosesse is ontleed volgens outomatisasievlak. Die aktiwiteite is ontleed teen elke vlak van outomatisasie gebaseer op inligting van bestaande vervaardigingsaanlegte. Indien die beste outomatisasievlakke vir alle parameters ooreenstem, dan is die optimale vlak van outomatisasie bereik. Indien nie, is verbeterings en/of addisionele oorwegings nodig om die outomatisasievlak te optimiseer. Die resultaat van die ontleding toon dat die grootste mate van outomatisasie nie noodwendig die beste is in terme van koste en gehalte nie, en dat ' $n$ mate van 'de-outomatisasie' benodig word. Die ontleding toon verder dat lae vlakke van outomatisasie kan lei tot swak produkgehalte en lae produktiwiteit. Die beste outomatisasiestrategie moet dus gebaseer word op ' $n$ ontleding van al die prosesaspekte in 'n plaaslike konteks.

\footnotetext{
${ }^{1}$ The author was enrolled for the M Tech (Industrial Engineering) Degree at the Nelson Mandela Metropolitan University
} 


\section{INTRODUCTION}

The automotive industry today is the epitome of mass production, mass marketing, and mass consumption. Production technology becomes more significant owing to the ever-growing number of suppliers and competitors in the market. Increasing globalisation causes stronger competition among the producing companies. Markets convert from sales to consumer markets. Progressive automation arose in response, as it seemed to be the only competitive strategy. However, a high level of automation can lead to less flexible automation systems: the products are difficult to customise to extremely complex automation systems, which are expensive. According to studies done by the Fraunhofer Institute, 36\% of the companies that have experience with automated solutions now believe that they exaggerated the need for automation in the past [1]. Therefore, the choice of level of automation of a production system is an important management decision.

The $V W$ procedure for introducing a new vehicle is represented in Figure 1, showing that plant location plays an important role in process planning and preparation. The choice of plant location depends on, among other things, the personnel and energy costs, the level of education, skills and motivation of personnel, and market conditions. On the other hand, the plant location determines the level of automation of assembly lines.

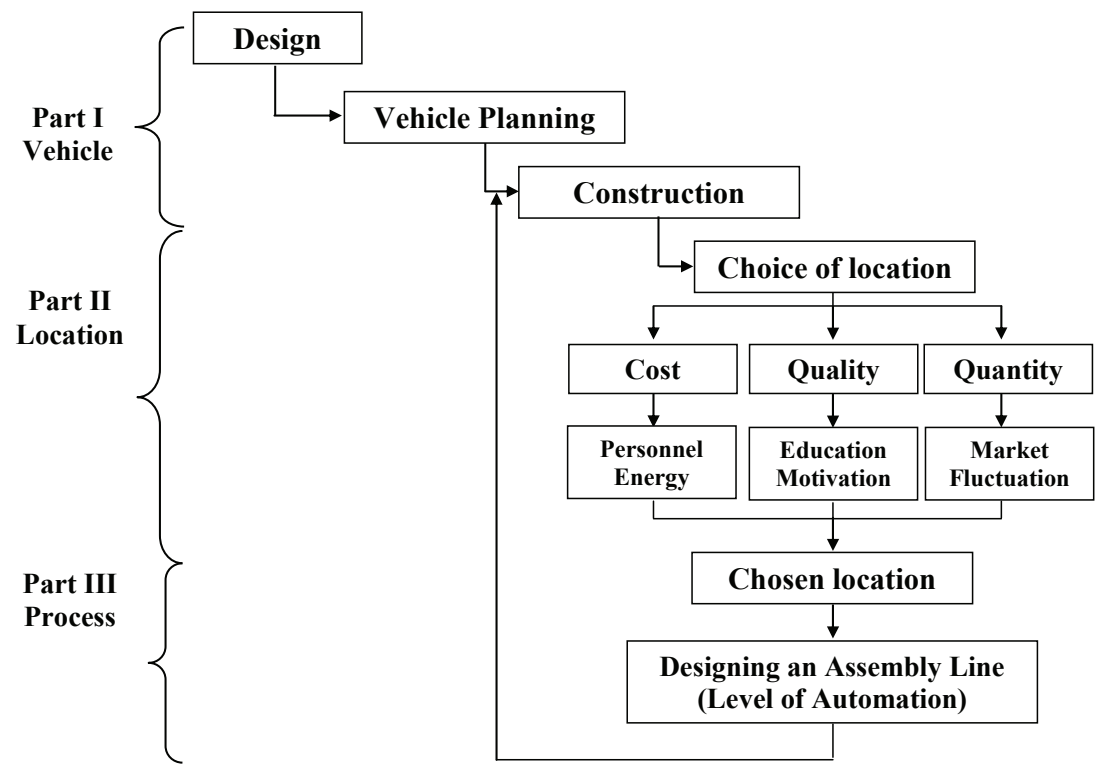

Figure 1: General procedure for introducing a new vehicle 
The analysis of the assembly lines of $V W$ at the three production sites was done in order to determine the automation/de-automation strategies by combining aspects of manufacturing systems such as costs, productivity, quality, and flexibility. The sites studied in this research are the Golf $A 5$ assembly line at the mother plant in Wolfsburg, Germany; the Touran assembly line at the Auto5000 GmbH in Wolfsburg; and the Golf $A 5$ assembly line in Uitenhage, South Africa. The aim of the analysis is to determine optimal levels of automation at the three production sites, in order to make recommendations to automate or de-automate particular sections of the assembly processes.

\section{THEORETICAL RATIONAL}

\subsection{Strategies and automation}

The study of Advanced Manufacturing Technologies (AMTs) and their relationship with business strategy receives much scholarly attention. It is widely recognized that AMTs are a major determinant of strategy - and vice versa. An increasing number of researchers frequently posit that maximum benefit will accrue if there is a fit between AMTs employed by the firm [2]. In pursuing such a strategy, the emphasis is on efficiency and on the rigorous pursuit of cost reduction from all possible sources, which is regarded as a cost-leadership approach [2]. A low-cost strategy represents attempts by firms to generate a competitive advantage by becoming the lowest cost producer in an industry [3]. On the other hand, firms can pursue differentiation strategies that emphasise a chosen form of uniqueness that stems from the product, process, or service [4]. Differentiation strategies, in an automotive context, can relate to product design, manufacturing, logistics, marketing, IT, etc. Typically, manufacturing units serving a differentiation strategy tend to have more complex product lines and several discontinuities in the process side to facilitate greater product variety [5]. So flexible manufacturing and assembly is an appropriate differentiation strategy in the automotive industry.

Many authors have argued that under certain industry conditions it is possible for firms to pursue simultaneously both cost-leadership and differentiation strategies orientations [6]. The implication is that pursuing a low-cost strategy requires the process side of manufacturing to be tightly integrated for effective cost minimisation [2]. Therefore, a combination of both strategies is appropriate in this case, as the goals are to design cost efficient car assembly systems and to achieve high productivity, consistent quality, and flexibility.

In order to compare different manufacturing technologies, based on the methodology proposed by the Fraunhofer Institute, the final car assembly processes are classified according to the level of automation. The level of automation represents the portion of automated functions of a system in relation to the complete function of the system [7]. Each level of automation is associated with certain costs, which are explained below.

\subsection{Manufacturing costs}

In manufacturing, the total cost per unit versus the level of automation can be 
represented graphically as shown in Figure 2 [8]. As can be seen, the personnel costs decrease proportionally to the growing level of automation. At the beginning, economically justifiable operations are automated first; therefore the automation cost increase almost linearly. Later, the expenditure increases over-proportionally because of the rising complexity of the system. So reaching complete automation causes the automation cost to increase exponentially while the personnel costs decrease only linearly, indicating a higher total cost.

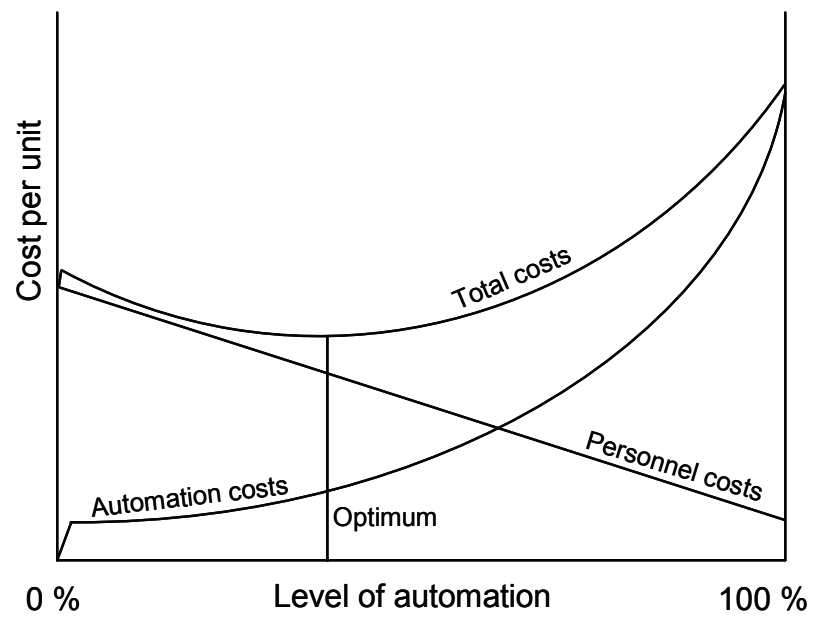

Figure 2: Graph of cost versus level of automation

For the cost calculations, the relevant cost approach is used where only the costs that make the largest contribution are taken into account [9].

The following cost types are necessary for the realisation of the assembly process:

- $\quad$ Personnel (all carrying out and planning activities in the assembly process; personnel costs consist of wage / salary and social costs; they essentially depend on personnel qualification)

- Operating material (installations for assembly and transport; operating material costs include all costs for running the operating material)

- $\quad$ Material (only consumables are relevant)

- Information 


\subsection{Quality indices}

Quality is a top priority competition factor that should be integrated into all the processes of a company. Quality is characterised by the index system, which is defined as a compilation of quantitative variables, in which individual indices belong to each other and are supplementary to each other, or explain each other in an objective and practical way. Thus, all these collected factors are focused on one common paramount target. An index is formed by the following elements: character of information, ability to quantify facts, and specific form of information [10]. All the information in the index should be adequately defined to avoid ambiguity.

For manufacturing and assembly processes, the quality standards are specified by the output quality indices, which are as follows:

- $\quad$ The quota of quality defects that does not meet the quality requirements in production immediately, i.e. the ratio of defects to the whole production volume.

- $\quad$ The indices concerning the number of rejects and the rectification of rejects as well as their prevailing share of the whole production volume that shows the developing trend.

- $\quad$ The indices with regard to the individual/different types of defects in their relation to the total number of defects in the production.

- $\quad$ The indices referred to as customer complaints, that are an indication of quality defects which have remained undiscovered in the production process.

- $\quad$ Audit-notes, which are determined and assessed separately as indices by a company.

\subsection{Productivity indices}

The productivity indices are determined from a number of quantitative aspects, such as 'hard' facts and 'soft' facts [11]. 'Hard' facts are:

- $\quad$ The number of units that are planned to be built, the so-called scheduled number of units.

- $\quad$ The number of units that have actually been built.

- $\quad$ Times like the cycle times, manufacturing times, downtimes, and total working times.

- Number of employees involved in the production process. 
These are set in relation to:

- The availability of a production system with respect to the amount of standstill losses.

- $\quad$ The decreasing degree of performance with respect to loss of speed.

- $\quad$ The degree of quality depending on the number of parts which are produced with defects.

- $\quad$ The effectiveness of equipment as a whole with respect to the availability of production, the degree of performance, and quality.

- $\quad$ Productivity, which refers to the average number of vehicles built by one employee during a specified period of time and the number of vehicles built by all employees per hour.

'Soft' facts include:

- $\quad$ Flexibility to manufacture different units.

- $\quad$ The degree of complexity and its dependence on the different range of vehicle models compared to the basic model.

- $\quad$ Flexibility with regard to the possibility of producing many variations of a product on one line.

All the cost, quality, and productivity aspects are used for determining the best level of automation of the assembly processes at the three production sites, as shown in the following section.

\section{ANALYSES OF THE ASSEMBLY PROCESSES AT $V W$ IN GERMANY AND SOUTH AFRICA}

\subsection{Levels of automation}

The analysis was done for the final assembly of the Golf A5 and Touran models in Germany and the Golf A5 model in South Africa. The assembly processes are done at different levels of automation, making it possible to compare and choose the best automation strategy for the particular plant location.

The final assembly consists of the three main processes called Assembly Parts. Each Assembly Part in turn can be divided into Assembly Operations or Stations. Assembly Part 1 consists of five Assembly Stations, and includes roll forming of the tailgate and doors and fitting the cockpit. Assembly Part 2 also consists of five Assembly Stations and includes mainly the fitting of the power train and glass. Assembly Part 3 includes seven Assembly Stations, which are typically fitting the trim panels, cross members, bumpers, complete front end, wheels, and battery. 
To determine the level of automation, the Assembly Part is put in a matrix with Assembly Stations shown in columns and different manufacturing methods in rows according to the level of automation, from highest to lowest (Figure 3). The starting point for creating levels of automation is the assembly of the Golf A5 model at Wolfsburg because this process is the most automated; therefore it is assigned the highest level of automation. By de-automating one station at a time, the level of automation decreases. For example, Assembly Part 1 has five levels of automation because it consists of five Assembly Stations. The same is true for Assembly Part 2, whereas Assembly Part 3, with seven Assembly Stations, has seven levels of automation. The lowest level of automation is the manual assembly, which is how the Golf A5 model is assembled in Uitenhage. Between these is one level of automation that represents how the Touran model is assembled in Germany, which is a combination of automated and manual stations.

For all the stations of the Assembly Parts, the cycle times and the number of personnel are determined based on the available information from the three production methods and their combinations. The results are matrices with different levels of automation and the number of personnel needed for each station.

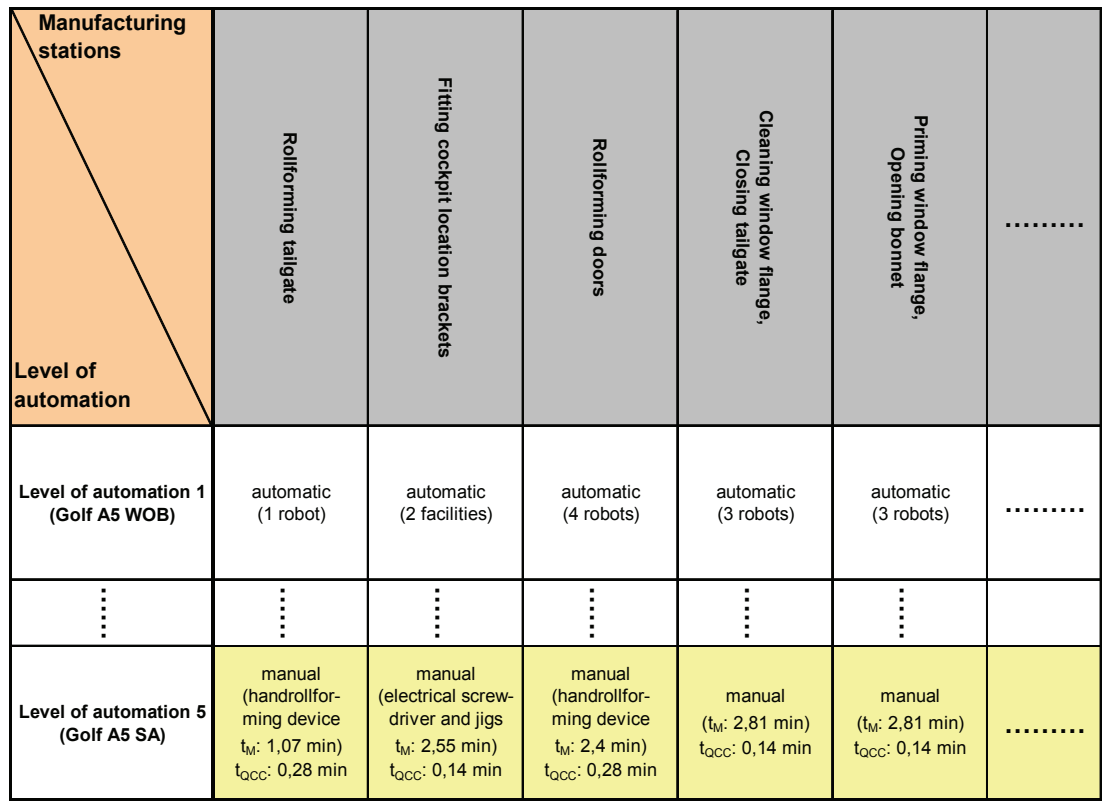

Figure 3: Example of the Assembly Part 1 matrix

With the matrices established, the basis for further analysis of each production site is in place, and the separate analyses of each production site can begin. 


\subsection{Manufacturing costs}

If every created level of automation (in the matrices) is provided with costs, the result will be the representation of all relevant costs that are differentiated according to resources, depending on the different levels of automation. By adding up the different costs of all stations, the most economical solution - and with it, the most economical level of automation of each matrix - can be examined. The total costs per unit for each level of automation in each Assembly Part are calculated with tables (one table for each level in each Assembly Part). Part of one of these tables is shown in Figure 4.

\begin{tabular}{|c|c|c|c|c|c|c|c|c|c|c|}
\hline \multicolumn{11}{|c|}{ Stations with parameters that are taken from Golf A5 Wolfsburg: } \\
\hline \multirow{3}{*}{ Station } & \multicolumn{10}{|c|}{ Pers } \\
\hline & \multicolumn{2}{|c|}{$\begin{array}{c}\text { Workers in } \\
\text { the line } \\
\left.\text { (c } c_{\text {yar }}\right)\end{array}$} & \multicolumn{2}{|c|}{$\begin{array}{c}\text { QCC- } \\
\text { workers } \\
\left(c_{\text {var }}\right)\end{array}$} & \multicolumn{2}{|c|}{$\begin{array}{l}\text { Reworker } \\
\left(c_{\text {var }}\right)\end{array}$} & \multicolumn{2}{|c|}{$\begin{array}{c}\text { Other } \\
\text { workers } \\
\left(c_{\mathrm{var}}\right)\end{array}$} & \multirow[b]{2}{*}{$t_{M}$} & \\
\hline & $t_{M}$ OWj & $C_{P_{2}} \mathrm{DW}_{\mathrm{W}}$ & $t_{M} Q Q_{C C}$ & $C_{P_{2} Q C C C_{j}}$ & $t_{M} R_{W j}$ & $C_{P_{2} R W_{j}}$ & $t_{M_{-} O w_{j}}$ & $c_{P}$. owj & & \\
\hline & \multicolumn{8}{|c|}{$c_{0}=\frac{t_{N} \cdot C_{1}}{t_{N,} \cdot d}$} & & \\
\hline Fitting cockpit location brackets & 0 & $0,00 €$ & 0 & $0,00 €$ & 0,127 & $0,10 €$ & 0,748 & $0,57 €$ & 0 & \\
\hline $\begin{array}{l}\text { Cleaning window flange, } \\
\text { Closing tailgate }\end{array}$ & 0 & $0,00 €$ & 0 & $0,00 €$ & 0,127 & $0,10 €$ & 0,748 & $0,57 €$ & 0 & \\
\hline $\begin{array}{l}\text { Priming window flange, } \\
\text { Opening bonnet }\end{array}$ & 0 & $0,00 €$ & 0 & $0,00 €$ & 0,127 & $0,10 €$ & 0,748 & $0,57 €$ & 0 & \\
\hline Applying cockpit glue & 0 & $0,00 €$ & 0 & $0,00 €$ & 0,127 & $0,10 €$ & 0,748 & $0,57 €$ & & \\
\hline Cockpit fitting 1 & 0 & $0,00 €$ & 0 & $0,00 €$ & 0,127 & $0,10 €$ & 0,748 & $0,57 €$ & & \\
\hline Cockpit fitting 2 & 0 & $0,00 €$ & 0 & $0,00 €$ & 0,127 & $0,10 €$ & 0,748 & $0,57 €$ & & \\
\hline $\begin{array}{l}\text { Removing cable box, } \\
\text { Remaining screw connections }\end{array}$ & 2,325 & $1,78 €$ & 0,14 & $0,11 €$ & 0 & $0,00 €$ & 0 & $0,00 €$ & & \\
\hline Remaining screw connections & 0 & $0,00 €$ & 0 & $0,00 €$ & 0,127 & $0,10 €$ & 0,748 & $0,57 €$ & 0 & $\overrightarrow{0,0}$ \\
\hline
\end{tabular}

Figure 4: Example of the cost table for Assembly Part 1

The calculation for the roll forming tailgate station is carried out as an example. The total cost is made up by labour, investment, energy, and overheads. (Material costs are not included because they are considered the same for all production sites.) All the costs are in $€ /$ unit.

The roll forming tailgate station is an automated station, so no direct labour cost is calculated. For the supporting staff, the cost per unit for the reworkers $\mathbf{C}_{P_{-}}{ } W_{j}$ is calculated as follows:

$$
\mathrm{C}_{\mathrm{P}_{-} \mathrm{RWj}}=\frac{t_{M_{-} R W_{j}} \cdot C_{P_{-} W}}{t_{S H} \cdot d_{W}}
$$

where: $\quad t_{M \_R W j}=$ manufacturing time of reworker of station $\mathbf{j}$, minutes/unit, $C_{P_{-} W}=$ personnel cost rate for the prevailing worker, $€$

$t_{S H}=$ a day shift time in minutes

$d_{W}=$ working days.

The cost of auxiliary workers $C_{P_{-} o w_{j}}$ is calculated with the same formula, but for a different manufacturing time: 
$C_{P_{-} O W j}=\frac{t_{M_{-} O W j} \cdot C_{P_{-} W}}{t_{S H} \cdot d_{W}}$

where: $t_{M_{\_} o_{j}}=$ manufacturing time of auxiliary worker of station $\mathrm{j}$, minutes/unit.

To calculate the cost of the supervisors, first the number of supervisors $n_{M j}$ for the chosen station has to be calculated (1 supervisor for 15 workers):

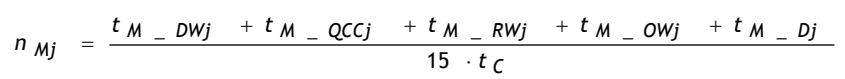

where: $\quad t_{M_{\_} D W_{j}}=$ manufacturing time worker in the line of station $\mathrm{j}$, minutes/unit,

$t_{M_{-} Q C C j}=$ manufacturing time QCC - worker of station $j$, minutes/unit,

$t_{M_{-} Q R W_{j}}=$ manufacturing time reworker of station $\mathrm{j}$, minutes/unit,

$t_{M \_O W_{j}}=$ manufacturing time other worker of station $\mathrm{j}$, minutes/unit,

$t_{M_{\perp} D j}=$ manufacturing time for loading of station $\mathrm{j}$, minutes/unit,

$t_{C}=$ cycle time, minutes/unit .

After that the personnel cost per unit for the supervisor $c_{P_{-} M j}$ can be calculated with the following formula:

$C_{P_{-} M j}=n_{M j} \cdot \frac{n_{S} \cdot C_{P_{-} M}}{n}$

where: $\quad n_{S}=$ number of shifts per day,

$C_{P_{-} M}=$ personnel cost rate for master, $€$,

$n=$ number of units per day.

Before calculating the other personnel cost per unit, it is necessary to determine the investment (capital) costs per unit, $c_{I N V j}$ :

$\mathrm{C}_{\mathrm{INVj}}=\frac{C_{I N V j}}{a \cdot n}$

where: $\quad C_{I N V j}=$ total investment costs for station $\mathrm{j}, €$, $\mathrm{a}=$ period of depreciation, years.

Then the personnel cost for maintenance per unit $c_{P_{-} M A i}$ can be calculated, which is assumed to be $50 \%$ of the investment cost per unit. The planning personnel cost per unit $C_{P_{-} P_{j}}$ is $7 \%$ of the investment cost per unit.

The personnel cost for industrial engineering $C_{P_{-} I E j}$ is calculated with the following formula:

$$
C_{P_{-} I E j}=\frac{\sum t_{M j}}{2} \cdot \frac{d_{W W} \cdot C_{P_{-} I E}}{d_{W}} \cdot \frac{1}{a \cdot n}
$$

where: $t_{M j}=$ manufacturing time of station $\mathrm{j}$ for the prevailing worker, minutes/unit, $d_{w w}=$ working day per week, $C_{P_{-} I E}=$ personnel cost rate for industrial engineering employee, $€$. 
The total personnel cost per unit has to be multiplied by a factor of 1.11 - i.e. increased by $11 \%$, to include the labour overhead cost.

The energy cost per unit $\mathrm{C}_{\mathrm{Ej}}$ is calculated as follows:

$$
c_{E j}=\frac{P_{E j} \cdot C_{P O W}}{n}+\frac{P_{E j} \cdot C_{W} \cdot t_{C}}{60}
$$

where: $P_{E j}=$ power for station $\mathrm{j}, \mathrm{kW}$

$$
\begin{aligned}
& C_{P O W}=\text { energy cost rate for power for the prevailing location, } € / \mathrm{kW} \\
& C_{W}=\text { energy cost rate for work for the prevailing location, } € / \mathrm{kWh}
\end{aligned}
$$

The equipment cost per unit $c_{E Q j}$ is determined as follows:

$$
C_{E Q j}=\frac{1}{n} \cdot \frac{C_{I N V j}}{C_{I N V_{-} W O B}} \cdot C_{E Q_{-} W O B}
$$

where: $C_{I N V_{\text {WOB }}}=$ total investment cost for all Assembly Parts for Golf A5 Wolfsburg, $€$,

$€$.

$$
C_{E Q \text { WOB }}=\text { total equipment cost for all Assembly Parts for Golf A5 Wolfsburg, }
$$

The additional operating expenses $c_{E j}$ are calculated as follows:

$$
c_{E j}=\frac{P_{O S j} \cdot C_{P O W}}{n}+\frac{P_{O S j} \cdot C_{W} \cdot t_{C}}{60}
$$

where: $P_{o s j}=$ power to produce compressed air for station $\mathrm{j}, \mathrm{kW}$,

$C_{\text {POW }}=$ energy cost rate for power for the prevailing location, $€ / \mathrm{kW}$,

$C_{W}=$ energy cost rate for work for the prevailing location, $€ / \mathrm{kWh}$.

By adding up all the costs per unit of each Assembly Station, the total costs of the whole Assembly Part for a specified level of automation is determined for each production site. Owing to differences in labour and running costs, each production site will have different total costs for the same Assembly Part. Figure 5 shows the total costs for the Golf A5 model produced in Germany with the present level outlined in bold, while the optimal level is shown in bold and shaded.

As can be seen for Assembly Part 1, the first level of automation is the optimal level of automation because it has the lowest costs. This level also predominates in practice. Therefore Assembly Part 1 is designed optimally. Workers and investment costs constitute the greatest share of the total cost per unit. The cockpit fitment station is the most expensive in this Assembly Part. With a decreasing level of automation, the other workers and investment costs take a smaller and smaller part, but costs for direct workers in the line increase accordingly. This is the main reason why even the second level of automation is more expensive than the first. The other types of cost make up only a small part of the total costs per unit. 
In Assembly Part 2 the fourth level of automation is optimal. The cost of workers in the line increases whereas, on the other hand, costs for all the other workers - as well as investment in equipment - do not increase in the same way. Thus, in order to reach the optimal level of automation, the stations stamping vehicle identity numbers, fitting the gearshift, closing the bonnet, and fitting all the windows have to work in the same way as in the assembly line of the Auto5000 GmbH.

\begin{tabular}{cccc}
$\begin{array}{c}\text { Level of } \\
\text { Automation }\end{array}$ & $\begin{array}{c}\text { Assembly } \\
\text { Part 1 }\end{array}$ & $\begin{array}{c}\text { Assembly } \\
\text { Part 2 }\end{array}$ & $\begin{array}{c}\text { Assembly } \\
\text { Part 3 }\end{array}$ \\
\hline 1 & $1,00 €$ & $1,20 €$ & $1,20 €$ \\
2 & $1,10 €$ & $1,30 €$ & $1,10 €$ \\
3 & $1,20 €$ & $1,10 €$ & $1,10 €$ \\
4 & $1,30 €$ & $1,00 €$ & $1,00 €$ \\
\hline 5 & $1,40 €$ & $1,40 €$ & $1,30 €$ \\
6 & & & $1,40 €$ \\
7 & & & $1,50 €$
\end{tabular}

Figure 5: Matrix of the total costs per unit of the Golf A5 model produced in Germany

In Assembly Part 3, the fourth level of automation is also optimal. On the first level, the investment costs constitute the greatest part of the total cost per unit, followed by the personnel cost for maintenance, reworkers, and other workers. As in Assembly Part 2, the cost of workers in the line increases with decreasing automation, while the cost of reworkers, other workers, and maintenance decreases until the cost optimum is reached in level 4. Thereafter the cost of workers in the line increases accordingly, which makes every further de-automation uneconomical. In order to put level 4 into practice as an optimal level of automation, the stations opening the bonnet, putting in and fitting the CW trim panel, putting in and fitting the battery, fitting the cross member and the rear bumper have to be designed using the Auto $5000 \mathrm{GmbH}$ pattern. The total costs per unit of the production site of the Auto5000 $\mathrm{GmbH}$ are shown in Figure 6.

As can be seen, for Assembly Part 1 the third level of automation is optimal (marked red). At this level, the highest cost per unit is the workers on the line, followed by investment costs. But in reality the automation level is level 4 (dotted fields). To reach the optimal level, the stations fitting cockpit location brackets and cockpit fitting 1 and 2 have to be designed to operate fully automatically, as on the Golf A5 model assembly line.

In Assembly Part 2, the fourth level of automation is optimal - which also predominates in practice. So Assembly Part 2 is designed optimally. The most expensive station of this Assembly Part is fitting the complete power train combined with all under-bodywork. 


\begin{tabular}{cccc|}
$\begin{array}{c}\text { Level of } \\
\text { Automation }\end{array}$ & $\begin{array}{c}\text { Assembly } \\
\text { Part 1 }\end{array}$ & $\begin{array}{c}\text { Assembly } \\
\text { Part 2 }\end{array}$ & $\begin{array}{c}\text { Assembly } \\
\text { Part 3 }\end{array}$ \\
\hline 1 & $1,30 €$ & $1,20 €$ & $1,30 €$ \\
\hline 2 & $1,20 €$ & $1,30 €$ & $1,20 €$ \\
\hline 3 & $1,00 €$ & $1,10 €$ & $1,10 €$ \\
\hline 4 & $1,10 €$ & $1,00 €$ & $1,00 €$ \\
\hline 5 & $1,40 €$ & $1,40 €$ & $1,40 €$ \\
\hline 6 & & & $1,50 €$ \\
\hline 7 & & & $1,60 €$ \\
\hline
\end{tabular}

Figure 6: Matrix of the total costs per unit of the Touran model produced in Germany

In Assembly Part 3, the fourth level of automation also represents the optimum; but in practice level 6 predominates, which again requires a higher level of automation in the assembly line of the Touran model at the Auto5000 $\mathrm{GmbH}$. On level 6, the fitting of the front end is the most expensive station because of the high personnel costs for workers in the line. The second most expensive station is the pre-mounting and fitting of wheels. Both of the stations have high investment costs as well. Therefore, both of these stations and the station placing the spare wheel in the boot have to work fully automatically as done in the Golf A5 model assembly line at the same location.

\begin{tabular}{cccc}
$\begin{array}{c}\text { Level of } \\
\text { Automation }\end{array}$ & $\begin{array}{c}\text { Assembly } \\
\text { Part 1 }\end{array}$ & $\begin{array}{c}\text { Assembly } \\
\text { Part 2 }\end{array}$ & $\begin{array}{c}\text { Assembly } \\
\text { Part 3 }\end{array}$ \\
\hline 1 & $1,40 €$ & $1,40 €$ & $1,60 €$ \\
\hline 2 & $1,30 €$ & $1,30 €$ & $1,50 €$ \\
\hline 3 & $1,20 €$ & $1,20 €$ & $1,30 €$ \\
\hline 4 & $1,10 €$ & $1,10 €$ & $1,20 €$ \\
\hline 5 & $1,00 €$ & $1,00 €$ & $1,10 €$ \\
\hline 6 & & & $1,40 €$ \\
\hline 7 & & & $1,00 €$ \\
\hline
\end{tabular}

Figure 7: Matrix of the total costs per unit of the Golf A5 model produced in South Africa

For the Golf A5 model produced in South Africa (Figure 7), most of the manual levels of automation reach the optimal level, and this is also done in practice at the moment. Therefore, in this step of the analysis, no changes of stations or other operations are necessary. In Assembly Part 1, the most expensive station is fitting the cockpit, taking nearly half of the total cost per unit. In Assembly Part 2, fitting 
the power train combined with the whole under-bodywork constitutes the highest cost per unit - more than half of the total. In Assembly Part 3, pre-mounting and fitting wheels show the highest part of the total cost. It is possible that costs can be further lowered by reducing the level of automation at the production site in South Africa. However, there are no data available for manufacturing times and costs for facilities with even less automation. Also, further de-automation could lead to lower quality.

\subsection{Quality}

The quality indices for the three production sites are shown in one table (Figure 8). These include Field data, Audit data of vehicle and process, Vehicle Preparation Centre (VPC) data and Direct Runner Rates (DRR). Field data show the quality of vehicles from a customer's point of view, with the recording of trouble cases (T.C.) per vehicle. Vehicle auditing is an element of the Quality Assurance System, which in a snapshot judges the effectiveness of the Quality Management System on the basis of quality delivered. The Vehicle Preparation Centre, located in Japan, records defects in vehicles delivered from Wolfsburg and Uitenhage in a $100 \%$ control. DRR is an index by which each plant is measured, indicating the number of vehicles which get 'o.k.' status at the final checkpoint (CP8) of the production process. DRR is also included on CP7 to show how many 'o.k.' vehicles have been released from the assembly. The effectiveness of the Quality Management Systems is judged by the Process Audits, expressed as a percentage.

\begin{tabular}{|c|c|c|c|c|c|c|c|c|}
\hline $\begin{array}{l}\text { Manufactu- } \\
\text { ring stations } \\
\text { Level of } \\
\text { automation }\end{array}$ & 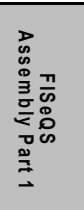 & 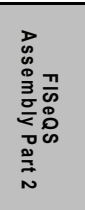 & 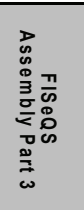 & $\begin{array}{l}\frac{\pi}{0} \\
\frac{\pi}{2} \\
0 \\
0 \\
\frac{0}{ \pm}\end{array}$ & 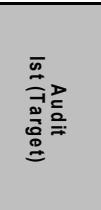 & ¿ & 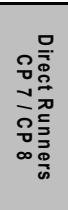 & $\begin{array}{l}D \\
0 \\
0 \\
0 \\
0 \\
0 \\
0 \\
D \\
D \\
0 \\
\equiv\end{array}$ \\
\hline \multirow{2}{*}{$\begin{array}{l}\text { Level of automation } \\
\text { (Golf A5 WOB) }\end{array}$} & 0,01345 & 0,02796 & 0,00465 & 0,05432 & $80(90)$ & 2,44 & $58 / 62$ & 94 \\
\hline & T.C./veh. & T.C./veh. & T.C./veh. & T.C./veh. & Audit Points & T.C./veh. & $\%$ & $\%$ \\
\hline & & & & & & & & \\
\hline \multirow{2}{*}{$\begin{array}{l}\text { Level of automation } \\
\text { (Auto5000 WOB) }\end{array}$} & 0,03872 & 0,01235 & 0,01987 & 0,01076 & $82(90)$ & 0.87 & $69 / 95$ & 91 \\
\hline & T.C./veh. & T.C./veh. & T.C./veh. & T.C./veh. & Audit Points & T.C./veh. & $\%$ & $\%$ \\
\hline \multirow{2}{*}{$\begin{array}{l}\text { Level of automation } \\
\text { (Golf A5 SA) }\end{array}$} & 0,10984 & 0,03561 & 0,96543 & 0,02345 & $92(90)$ & 2,23 & $81 / 89$ & 92 \\
\hline & T.C./veh. & T.C./veh. & T.C./veh. & T.C./veh. & Audit Points & T.C./veh. & $\%$ & $\%$ \\
\hline
\end{tabular}

Figure 8: Matrix of the quality analysis

The next step is an investigation into the optimal level of automation in respect of quality. All other quality factors can only be concluded from these results because the data are assigned to the whole examined assembly area. All the above quality indices values are assessed as follows:

- $\quad$ Rank all values in comparison to each other (best, second best, and worst). 
Allocate points to each status:

- $\quad$ The best gets 3 points, the second best gets 2 points, and the worst gets 1 point.

- $\quad$ Attach importance to each value:

The most convincing values are the assembly Trouble Cases (TC); they get the highest weight and are multiplied by the factor 3 .

- $\quad$ All the other values go down in assessment in single weight.

- $\quad$ Total all points: The best existing level of automation has the most points.

The analysis showed that the Auto5000 Wolfsburg manufactures best according to all the quality indices. The second part of the task is to find the theoretical optimal automation. Therefore each Assembly Part that delivers the fewest trouble cases per vehicle is investigated. These collected data are summarized in one theoretical optimal level of automation.

\subsection{Productivity and flexibility}

On the basis of the above matrices, the productivity figures are examined in relation to the number of workers. These workers are later seen in relation to the vehicles built and the time needed for that. These relations are the indices of productivity taken into consideration in this analysis. The result of this analysis confirms that a highly automated way of manufacturing is also highly productive when taking into account that the smallest number of employees produces the largest number of vehicles - as can be seen from the comparison shown in Figure 9. On the other hand, the calculation of effectiveness shows that highly-automated production is susceptible to faults and trouble cases because of its complexity. On account of this, a high number of faultless units can be reached, besides other methods, when produced at a lower automated level, which includes the integration of highly skilled employees.

Flexibility of production equipment is too difficult to quantify in financial terms. Also, product variations cannot be considered in this case since the automotive production equipment is specifically designed for a range of vehicle models. Nevertheless, the production equipment should have sufficient capacity to accommodate a limited increase in production quantities. Therefore, in determining the levels of flexibility of Assembly Parts, the focus is on two aspects:

- $\quad$ the variation of production quantities, and

- $\quad$ the number of workers required. 


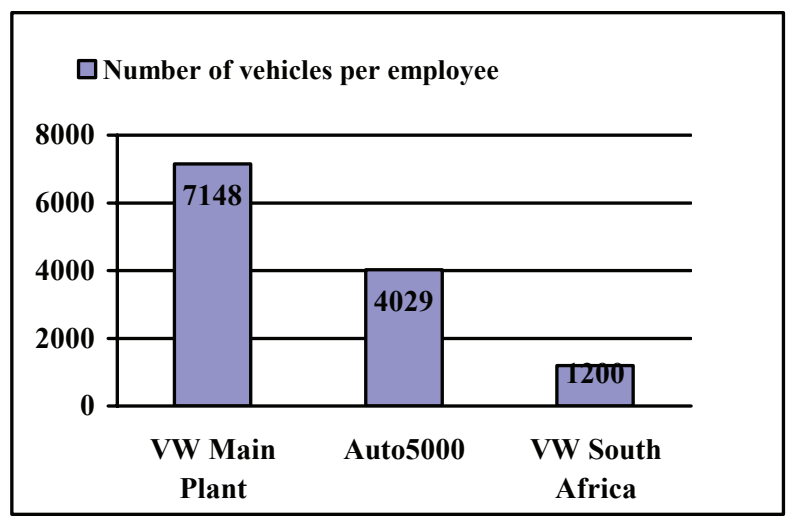

Figure 9: Annual vehicle quantities per employee

From this point of view, the most flexible is the production system that has to change the least to cope with the increase/decrease of production quantities - i.e. a minimum variation in the number of workers. The results of the analysis for a $\pm 20 \%$ variation in production quantities are shown in Figure 10. The bold and shaded fields show the most flexible production system, with little or no variation in the number of workers, while the underlined fields represent the least flexible production systems with a large variation in the number of workers needed to accommodate different production quantities. From these tables, the optimal levels of automation are chosen in respect of flexibility. As can be seen from Figure 10, there is more than one optimal level of automation for all the assembly processes, except for Assembly Part 1 at the VW main plant.

\section{RESULTS AND DISCUSSION}

The levels of automation of the assembly processes in respect of three main aspects - costs, quality, and quantity - are compared to obtain the optimal levels for each production site. If the different optima correspond with each other, the total optimum for the individual Assembly Part has been found. Otherwise, if the optima show differences in a certain Assembly Part, a further examination has to be carried out. In the combination of the optima, the optimal levels of costs are defined as the basis. Both of the other aspects are compared with the optimal level of costs to find a total solution for each production site. The results are shown in Figure 11.

\subsection{Production of the Golf A5 model in Wolfsburg}

For Assembly Part 1, level 1 is the optimal automation level from a cost point of view, which represents actual assembling in practice. The productivity indices show the same optimum. But the differences between the optimal level of costs and quality have to be remedied. The difference between the first and the third level of 


\section{Golf A5 Wolfsburg}

Number of workers

\section{Assembly Part $1 \quad$ Assembly Part $2 \quad$ Assembly Part 3}

Level

Units

$$
\begin{array}{lllllllllllllllll}
1 & 2 & 3 & 4 & \underline{5} & 1 & 2 & 3 & 4 & \underline{5} & 1 & 2 & 3 & 4 & 5 & 6 & \underline{7}
\end{array}
$$

$\begin{array}{llllllllllllllllll}-20 \% & 8 & 10 & 14 & 19 & \underline{19} & 7 & 10 & 10 & 9 & \underline{34} & 6 & 6 & 8 & 8 & 13 & 15 & \underline{18}\end{array}$

$\begin{array}{llllllllllllllllll}\text { Actual } & 9 & 11 & 14 & 19 & \underline{22} & 8 & 10 & 11 & 12 & \underline{42} & 6 & 8 & 8 & 8 & 13 & 17 & \underline{20}\end{array}$

$\begin{array}{llllllllllllllllll}+20 \% & 10 & 13 & 18 & 25 & \underline{28} & 9 & 12 & 14 & 14 & \underline{48} & 6 & 8 & 10 & 8 & 14 & 18 & \underline{23}\end{array}$

\section{Auto 5000 Wolfsburg}

Number of workers

\section{Assembly Part 1 \\ Assembly Part 2 \\ Assembly Part 3}

Level

Units

$\begin{array}{cccccccccccccccccc}-20 \% & 8 & 10 & 13 & 18 & \underline{18} & 7 & 10 & 10 & 9 & \underline{32} & 6 & 6 & 8 & 8 & 12 & 15 & \underline{18} \\ \text { Actual } & 9 & 11 & 14 & 19 & \underline{21} & 8 & 10 & 10 & 10 & \underline{39} & 6 & 8 & 8 & 8 & 13 & 17 & \underline{20} \\ +20 \% & 10 & 12 & 15 & 23 & \underline{25} & 9 & 11 & 11 & 11 & \underline{45} & 6 & 8 & 8 & 8 & 14 & 18 & \underline{23}\end{array}$

Golf A5 SA

Number of workers

\section{$\begin{array}{lll}\text { Assembly Part } 1 & \text { Assembly Part } 2 & \text { Assembly Part } 3\end{array}$}

Level

$\begin{array}{llllllllllllllllll}\text { Units } & 1 & 2 & 3 & 4 & \underline{5} & 1 & 2 & 3 & 4 & \underline{5} & 1 & 2 & 3 & 4 & 5 & 6 & \underline{7}\end{array}$

\begin{tabular}{llllllllllllllllll}
$-20 \%$ & $\underline{4}$ & 6 & 8 & 10 & $\underline{8}$ & 4 & 6 & 8 & 7 & $\underline{11}$ & 4 & 5 & 7 & 7 & 9 & 9 & $\underline{9}$ \\
\hline Actual & $\underline{5}$ & 6 & 8 & 10 & $\underline{9}$ & 4 & 6 & 8 & 7 & $\underline{12}$ & 4 & 5 & 7 & 7 & 9 & 9 & $\underline{9}$ \\
$+20 \%$ & $\underline{5}$ & 6 & 8 & 10 & $\underline{9}$ & 4 & 6 & 8 & 7 & $\underline{14}$ & 4 & 5 & 7 & 7 & 9 & 9 & $\underline{10}$
\end{tabular}

Figure 10: Optimal levels of automation in respect of productivity and flexibility 
automation from a quality point of view is 0.005 trouble cases per vehicle. A more detailed examination of the operations with regard to quality aspects revealed that the assembly stations of roll forming tailgate as well as roll forming of doors cause this difference. This is attributed to the robotic station, which allows only a very small tolerance for assembling. If this tolerance margin is not kept, the robot is not able to react appropriately, because an automatic station is not flexible enough to compensate for abrupt tolerance variations. In order to achieve better quality, an improvement to the adjustment of the robot, more appropriate maintenance of the robot, or a further development of the roll forming tool for robots should be investigated.

\begin{tabular}{|c|c|c|c|c|c|c|c|c|c|}
\hline \multirow{3}{*}{ Index } & \multicolumn{3}{|c|}{$\begin{array}{l}\text { Golf } A 5 \\
\text { Wolfsburg }\end{array}$} & \multicolumn{3}{|c|}{$\begin{array}{l}\text { Touran at } \\
\text { Auto5000 } \\
\text { Wolfsburg }\end{array}$} & \multicolumn{3}{|c|}{$\begin{array}{c}\text { Golf A5 } \\
\text { Uitenhage }\end{array}$} \\
\hline & \multicolumn{9}{|c|}{ Optimal level of automation of Assembly Parts } \\
\hline & AP1 & AP2 & AP3 & AP1 & AP2 & AP3 & AP1 & AP2 & $\begin{array}{c}\mathrm{AP} \\
3\end{array}$ \\
\hline Cost & 1 & 4 & 4 & 3 & 4 & 4 & 5 & 5 & 7 \\
\hline Quality & 3 & 4 & 4 & 3 & 4 & 1 & 3 & 4 & 1 \\
\hline Productivity/flexibility & 1 & 2 & 4 & 2 & 3 & 4 & 4 & 4 & 6 \\
\hline $\begin{array}{c}\text { Present automation } \\
\text { level }\end{array}$ & 1 & 1 & 1 & 4 & 4 & 4 & 5 & 5 & 7 \\
\hline $\begin{array}{c}\text { Recommended } \\
\text { automation level }\end{array}$ & 1 & 4 & 4 & 3 & 4 & 3 & 5 & 5 & 7 \\
\hline
\end{tabular}

Figure 11: Optimal levels of automation

For Assembly Part 2, the determination of the optimal level of costs and quality delivers the same level of automation as the optimal - level 4. However, the actual level of automation is level 1; and in productivity terms, levels 1 and 2 demonstrate the best options. But level 4 shows rising productivity compared to a decreasing number of units. And, additionally, it provides better flexibility because the operations are done manually and can be modified easily. Therefore, the actual level of automation in Assembly Part 2 has to be de-automated to reach the total optimal level - but the improvement of the quantity indices has to be considered.

For Assembly Part 3, the results of costs, quality, and productivity are also the same, which is level 4 , whereas the actual level of automation is 1 , indicating that a lower automation level is to be preferred for this operation.

\subsection{Production of the Touran model at Auto5000 GmbH in Wolfsburg}

In the Auto5000 GmbH, for Assembly Part 1, level 3 is the optimal level with regard to costs and quality, whereas the actual level of automation is level 4. Regarding flexibility and productivity, level 2 is optimal. Since the cost and quality indices 
point to a lower lever of automation, Level 3 is recommended for Assembly Part 1 (Figure 11).

As for Assembly Part 1, in Assembly Part 2 the optimal levels of automation regarding cost and quality correspond to each other. But for this Assembly Part, level 4 represents the actual level of automation. Although the productivity/flexibility index points to higher automation (level 3), keeping the present method of production is recommended. So Assembly Part 2 is optimally designed.

For Assembly Part 3, the results of costs (level 4) and quality (level 1) do not correspond, which is the main concern. It appears that even with the extensive training programme that takes place at the Auto5000 plant, consistent quality is not possible without automation for this assembly process. Concerning productivity, levels 3 or 4 are the optimum. Based on the results, Assembly Part 3 should be automated to level 3 to improve quality.

\subsection{Production of the Golf A5 model in Uitenhage}

For the production site in Uitenhage, all the Assembly Parts have similar discrepancies for all the indices. The quality index points to a higher level of automation, while the cost and productivity indices show that the present methods are the most economical. The above-mentioned argument -that manual assembly is as good in quality terms as automatic assembly, or even better - is not valid for the manufacturer in Uitenhage. For example, a comparison of the assembly of roll forming tailgate and doors in Uitenhage and at the Auto5000 GmbH shows that 0.101 more trouble cases per vehicle are recorded in Uitenhage. The reasons behind the poor quality of the manual operations will have to be investigated. In this study, it is assumed that quality can be raised to levels similar to the other production sites. Therefore, it is recommended that the levels of automation of the Assembly Parts not be changed, but that quality issues be investigated and improved.

\section{SUMMARY}

In this research, the assembly lines of three different production sites of VW AG the Golf A5 assembly line in Wolfsburg, the Touran assembly line in the Auto5000 $\mathrm{GmbH}$ in Wolfsburg, and the Golf A5 assembly line in South Africa - were analysed to find the optimal level of automation in order to recommend the best automation strategy for a production site.

The methodology is based on obtaining the optima for the costs, quality, productivity, and flexibility indices by examining all possible production methods for a particular process at a particular plant location. The optima are then compared, and if found to be the same, the production process is considered to be optimally designed. If the optima do not correspond, the necessary adjustments are made to find the best solution. This approach combines all the major factors of the production system and product quality in order to achieve a good balance in designing and optimising manufacturing processes. Although the cost optimum is the basis of the analysis, other factors such as quality and flexibility also play an important role in decision-making. 
The study of the Golf A5 assembly line in Wolfsburg illustrates that the examined Assembly Parts 2 and 3 have to be de-automated to achieve the optimal level of automation. Assembly Part 1 is optimally designed; however, quality improvement is required. The actual level of automation in Assembly Part 2 has to be de-automated to reach the total optimal level, but an improvement in the quantity indices has to be considered. In Assembly Part 3, the actual level of automation also has to be deautomated to reach the optimal level. Quality issues, as well as modifications in quantity, should also be kept in mind.

The examined Assembly Parts in the production site of the Auto5000 GmbH in Wolfsburg have to be automated according to the results obtained. This conclusion is valid for Assembly Parts 1 and 3, which have to be automated from their present levels of automation to reach an optimal level. The necessary variations in quantity have to be considered in both Parts. Additionally, in Assembly Part 3 quality improvements are needed. The actual level of automation in Assembly Part 2 represents the total optimal level of automation with regard to all indices. So this process is already optimally designed.

The existing levels of automation in the Golf A5 assembly line in Uitenhage are optimally designed according to the obtained results. However, especially from the point of view of quality, the processes have to be improved. The product at Auto5000 GmbH illustrates that manual assembly with high quality is possible in practice. So the manufacturing process in Uitenhage has to be adapted in order to produce better quality in the actual and optimal level of automation.

This technique is valuable for decision-making about the best automation strategy for new systems, or for optimising existing production systems with regard to automation/de-automation without compromising the high quality of products. The analysis is based on prior information of similar production systems with respect to cost and productivity. Some assumptions in terms of quality would be needed in case new processes are introduced.

The case study demonstrated that fully automated as well as completely manual processes are not the optimal in automotive assembly. It was also shown that the fictitiously determined levels of automation, consisting of automated and manual stations, are a better option if the combined effects of cost, quality, and flexibility are considered. This means that both long-term vision and logical procedures are as important as the efficient design of assembly lines to guarantee an efficient manufacturing process.

\section{ACKNOWLEDGMENTS}

The authors acknowledge the staff of VW AG Wolfsburg and Uitenhage, and in particular the department PWA-V (launching and production process optimisation in Wolfsburg), for providing the information used in this research.

\section{REFERENCES}

[1] Lay, G. and Schirrmeister, E., 2001. Sackgasse Hochautomatisierung? PIMitteilung. N 22, ISI, Fraunhofer. 
[2] Kotha, S. and Swamidass, P. M., 2000. Strategy, advanced manufacturing technology and empirical evidence from U.S. manufacturing. Journal of Operations Management, 18, 257-277.

[3] Porter, M., 1980. Competitive strategy: Techniques for analyzing industries and competitors. The Free Press, New York.

[4] Mintzberg, H., 1988. Generic strategies: toward a comprehensive framework. In Advances in Strategic Management, Vol. 5. JAl Press, Greenwich, CT.

[5] Kotha, S., and Orne, D., 1989. Generic manufacturing strategies: a conceptual synthesis. Strategic Management Journal 10/3, 211-231.

[6] Hill, C., 1988. Differentiation versus low cost or differentiation and low cost: a contingency framework. Academy of Management Review 13, 401412.

[7] Fichtmuiller, N., 1996. Rationalisierung durch flexible, hybride Montagesysteme, Heidelberg.

[8] Hartmann, M., 1993. Entwicklung eines Kostenmodells für die Montage Ein Hilfsmittel zur Montageanlagenplanung, Aachen.

[9] Ross, P., 2002. Bestimmung des wirtschaftlichen Automatisierungsgrades von Montage-Prozessen in der frühen Phase der Montageplanung, Munich.

[10] Tomys, A.K., 1995. Kostenorientiertes Qualitätsmanagement, Qualitätscontrolling zur ständigen Verbesserung der Unternehmensprozesse, Munich.

[11] Heinen, E., 1978. Industriebetriebslehre: Entscheidungen im Industriebetrieb, Gabler, 147. 